Published in final edited form as:

Mem Cognit. 2014 July ; 42(5): 794-805. doi:10.3758/s13421-013-0393-7.

\title{
Effects of Animacy and Noun-Phrase Relatedness on the Processing of Complex Sentences
}

\author{
Matthew W. Lowder and Peter C. Gordon \\ University of North Carolina at Chapel Hill
}

\begin{abstract}
Previous work has suggested that syntactically complex object-extracted relative clauses are easier to process when the head noun phrase (NP1) is inanimate and the embedded noun phrase (NP2) is animate compared to the reverse animacy configuration, with differences in processing difficulty beginning as early as NP2 (e.g., The article that the senator... versus The senator that the article...). Two eye-tracking-while-reading experiments were conducted to better understand the source of this effect. Experiment 1 showed that having an inanimate NP1 facilitated processing even when NP2 was held constant. Experiment 2 manipulated both animacy of NP1 and the degree of semantic relatedness between the critical NPs. When NP1 and NP2 were paired arbitrarily, the early animacy effect emerged at NP2. When NP1 and NP2 were semantically related, this effect disappeared, with effects of NP1 animacy emerging in later processing stages for both the Related and Arbitrary conditions. The results indicate that differences in the animacy of NP1 influence early processing of complex sentences only when the critical NPs share no meaningful relationship.
\end{abstract}

\section{Keywords}

eye-movements; relative clauses; animacy; complex sentences

Readers rely on multiple sources of linguistic information in order to arrive at the correct interpretation of a sentence. A central goal of psycholinguistics is to understand how readers use the information available to them to facilitate processing and whether some linguistic cues might be relied on more heavily than others. In particular, this paper examines how semantic properties of the noun phrases (NPs) of a sentence might influence the processing of syntactically complex sentences. Studies of syntactic complexity often draw a comparison between subject-extracted and object-extracted relative clauses (RCs). In a subject-extracted $\mathrm{RC}$ (SRC), as in (1a), the head NP serves as the subject of the action being described in the $\mathrm{RC}$, as well as the subject of the action described in the main clause. In contrast, the head NP of an object-extracted RC (ORC), as in (1b), serves as the object of the action being described in the RC.

(1a) The journalist that accused the senator caused a scandal after the election.

Address correspondence to: Matthew W. Lowder Department of Psychology, CB \#3270 University of North Carolina at Chapel Hill Chapel Hill, NC 27599-3270 mlowder@email.unc.edu. 
(1b) The journalist that the senator accused caused a scandal after the election.

Although these two sentences contain the exact same words and differ only in word order, ORCs are more difficult to process than SRCs - a standard finding that has been reported using many different paradigms (e.g., Caplan, Alpert, \& Waters, 1998; Caramazza \& Zurif, 1976; Ford, 1983; Holmes \& O’Regan, 1981; Just, Carpenter, Keller, Eddy, \& Thulborn, 1996; Wanner \& Maratos, 1978).

Recent work has identified a variety of lexical, semantic, and pragmatic factors that moderate the ORC-SRC asymmetry (e.g., Gennari \& MacDonald, 2008; Gordon, Hendrick, \& Johnson, 2001, 2004; Gordon, Hendrick, Johnson, \& Lee, 2006; Johnson, Lowder, \& Gordon, 2011; King \& Just, 1991; Traxler, Morris, \& Seely, 2002; Traxler, Williams, Blozis, \& Morris, 2005; Warren \& Gibson, 2002), with these findings being used in the evaluation of competing theoretical explanations of complex-sentence processing (see Gordon \& Lowder, 2012, for a review). One class of these explanations has focused on semantic and/or pragmatic factors that influence the relationships between key aspects of RC sentences. For example, King and Just (1991) showed that the ORC-SRC difference was substantially reduced when arbitrary noun-verb pairings (e.g., The robber that the fireman detested watched the program) were replaced by verbs that established meaningful sentential relationships (e.g., The robber that the fireman rescued stole the jewelry). This manipulation aids in ORC processing because the meaning of the sentence is consistent with what we know about the world (e.g., The robber stole; The fireman rescued), whereas a reverse pairing of NPs and verbs (e.g., The robber rescued; The fireman stole) would be inconsistent with world knowledge. In contrast, an ORC with arbitrary NP-verb pairings (e.g., The robber watched; The fireman detested) is more difficult to process because the NP-verb relationships are pragmatically reversible, making it impossible for readers to rely on their world knowledge to facilitate processing.

Other semantic/pragmatic approaches to RC processing have examined how the ORC-SRC asymmetry is moderated by broader semantic classes, such as NP animacy, in cases where world knowledge does not provide specific information about meaningful NP-verb links (Gennari \& MacDonald, 2008, 2009; Mak, Vonk, \& Schriefers, 2002, 2006; Traxler et al., 2002, 2005). For example, Tralxer et al. (2005) conducted an eye-tracking-while-reading experiment using sentences like those in (2). Results showed that the ORC-SRC difference was larger when the head NP (NP1) was animate and the embedded NP (NP2) was inanimate ( $2 \mathrm{~b}$ versus $2 \mathrm{a}$ ) than when the animacy configuration was reversed ( $2 \mathrm{~d}$ versus $2 \mathrm{c}$ ). Traxler et al. proposed that this effect occurred because readers adopt an active-filler strategy (e.g., Clifton \& Frazier, 1989; Frazier \& Clifton, 1989) during RC processing, such that all of the sentences in (2) are initially parsed as SRCs at the complementizer that. This strategy leads to an incorrect initial parse for ORCs (e.g., $2 \mathrm{~b}$ and $2 \mathrm{~d}$ ), which must be revised to yield the correct interpretation. Traxler et al. proposed that reanalysis of NP1 as the object of the RC verb was more difficult when it was animate $(2 b)$ than when it was inanimate (2d), thereby yielding a larger ORC-SRC difference when NP1 was animate than when it was inanimate.

(2a) The senator that skimmed the article was forgotten after the election. 
(2b) The senator that the article accused was forgotten after the election.

(2c) The article that accused the senator was forgotten after the election.

(2d) The article that the senator skimmed was forgotten after the election.

As in the King and Just (1991) example, manipulations of animacy raise issues related to the reversibility of NP-verb pairings. For example, the ORCs studied by Traxler et al. ( $2 \mathrm{~b}$ and 2d) each contain one animate NP, one inanimate NP, and an embedded action verb, which allows for only one semantically acceptable interpretation of each sentence (e.g., The senator skimmed the article is acceptable, whereas The article skimmed the senator is anomalous).

In Lowder and Gordon (2012) we challenged the notion that the animacy of NPs plays a direct role in the difficulty of processing ORCs. Comparing ORCs that differed only in the animacy of NP2, as in (3), we showed that the greater difficulty associated with having an inanimate compared to an animate NP2 (3b versus $3 a$ ) emerged entirely at the embedded verb. This pattern suggests that local processing difficulty emerges when an inanimate subject is integrated with an action verb (e.g., article accused), but that this difficulty does not contribute to broader-level RC effects, such as differences at the matrix verb.

(3a) The senator that the journalist accused was forgotten after the election.

(3b) The senator that the article accused was forgotten after the election.

A similar difficulty emerged when the inanimate subject and action verb appeared together in the main clause of the sentence (e.g., The article accused...) but was reduced when the two constituents appeared in separate clauses (e.g., The article that accused...). This pattern is consistent with other recent findings (Lowder \& Gordon, 2013; under review) showing that readers use sentence structure as a cue for determining the relative importance of different semantic relationships to the overall interpretation of a sentence, with important relationships being processed more deeply than less important ones. The semantic relationship between article and accused has reduced relevance and is processed less deeply when integration of the critical constituents occurs across a clause boundary, compared to when these two constituents appear together in the same clause.

Our experiment (Lowder \& Gordon, 2012) demonstrating that NP animacy affects local processes of subject-verb integration - but not broader processing of the complex relations in an ORC - manipulated the animacy of NP2 while holding NP1 constant (e.g., 3a vs. 3b). As such, its results only pertain to the animacy of the embedded NP, the processing of which was the focus of Traxler et al.'s. (2002, 2005) explanation of how animacy influences processing of RC sentences. However, Gennari and MacDonald (2008, 2009) have argued that the effect of animacy on the difficulty of ORCs (e.g., 2b vs. 2d) is due instead to differences in the animacy of NP1. They conducted a self-paced reading experiment using ORCs similar to the ones in (2b) and (2d), and found that ORCs with an animate NP1 (2b) were more difficult than ORCs with an inanimate NP1 (2d), an overall pattern that is consistent with previous findings, but in addition found that the difference first emerged at NP2 (i.e., before any verbs had been encountered). Gennari and MacDonald explain these results using an expectation-based framework that they call semantic indeterminacy (see 
also Hale, 2001; Levy, 2008; MacDonald \& Christiansen, 2002). According to this account, comprehension difficulty at each point in the sentence is a function of how statistically likely that continuation is, based on what has come before it. Thus, Gennari and MacDonald argue that when readers encounter an animate head followed by a complementizer (e.g., The senator that...), the probability that this stem will continue with an inanimate NP (e.g., The senator that the article...) is quite low. In contrast, an inanimate head followed by a complementizer (e.g., The article that...) is relatively more likely to continue with an animate NP (e.g., The article that the senator...). This, they argue, explains the processing differences at NP2 for (2b) versus (2d).

While Gennari and MacDonald's $(2008,2009)$ findings raise a variety of interesting questions, their interpretive focus on NP1 faces the same limitation as Traxler et al.'s interpretive focus on NP2; the source of the greater difficulty for (2b) versus (2d) could involve the animacy of NP1, the animacy of NP2, or both. This comparison is additionally complicated by the use of two different embedded verbs. Lowder and Gordon (2012) controlled for this by manipulating NP2 while keeping the rest of the sentence constant (see 3 ). The current study adopts a similar strategy in order to investigate the effects of NP1 animacy on RC processing and to provide evidence about the levels of processing at which animacy and world knowledge contribute to sentence processing.

\section{Experiment 1}

This experiment used eye-tracking during reading to determine how the processing of ORCs is affected by the animacy of NP1. The materials were based on those used in previous studies (Gennari \& MacDonald, 2008; Traxler et al., 2005), but were adapted such that only animacy of NP1 varied between the critical ORC sentences (see 4b-4c); SRC items using animate NP1s were also tested (see 4a). Thus, the comparison of (4a) and (4b) provides evidence about how ORC-SRC differences affect performance in sentences that are otherwise matched, whereas comparison of (4b) and (4c) provides evidence about how the animacy of NP1 in ORC sentences affects performance in sentences that are otherwise matched.

(4a) The senator that criticized the journalist accused the governor of embezzling millions of dollars. (SRC)

(4b) The senator that the journalist criticized accused the governor of embezzling millions of dollars. (ORC-Animate)

(4c) The article that the journalist criticized accused the governor of embezzling millions of dollars. (ORC-Inanimate)

Gennari and MacDonald's (2008) self-paced reading experiment provided evidence that having an inanimate NP1 facilitated ORC processing early in sentence comprehension during the reading of NP2. In contrast, Traxler et al.'s report of their eye-tracking data does not allow the exact locus of the difficulty to be pinpointed because they reported reading times for the $\mathrm{RC}$ region as a whole but not for individual words. The use of eye-tracking methodology in the current experiment allows us to assess whether manipulation of the animacy of NP1 influences ORC processing in early stages, later stages, or both. If NP1 
animacy influences the early stages of ORC processing as reported by Gennari and MacDonald (2008), we should observe longer reading times at NP2 for the ORC-Animate condition compared to the ORC-Inanimate condition, before the reader has fixated any of the verbs in the sentence. Although such a pattern would be consistent with the findings reported by Gennari and MacDonald, there are at least two possible explanations. Gennari and MacDonald (see also Staub, 2010) explain this effect in terms of semantic indeterminacy, proposing that the differences in processing times between these two conditions reflect differences in readers' expectations. However, we have argued previously that these early effects may instead be consistent with a memory-based framework of RC processing (see, e.g., Gordon et al., 2001, 2004; Gordon, Hendrick, \& Levine, 2002; Lewis \& Vasishth, 2005; Lewis, Vasishth, \& Van Dyke, 2006). This perspective conceptualizes difficulty with ORCs in terms of the cognitive mechanisms necessary to encode and store NPs in memory and then later retrieve them when they must be integrated with the verbs of the sentence. Thus, the early effect of animacy at NP2 may reflect greater effort at encoding, triggered by the readers' detection of a memory load that will have to be retrieved at a later point in the sentence (Gordon \& Lowder, 2012; Johnson et al., 2011).

In contrast, effects of NP1 animacy that emerge in relatively later measures (i.e., after the reader has begun processing the verbs) are most readily explained in terms of differences in how semantic reversibility affects retrieval of information from earlier in the sentence. Note that the ORC-Animate condition always contained two animate NPs, whereas the ORCInanimate condition contained one inanimate NP and one animate NP. Thus, the actions in the ORC-Animate condition were always semantically reversible, whereas the actions in the ORC-Inanimate condition often were not. For example, in the ORC The movie that the actress hated, readers can rely on semantic knowledge to assign the thematic role of agent to "actress" and patient to "movie." In contrast, in the ORC The director that the actress hated, readers cannot rely purely on semantic knowledge to assign thematic roles, as both "director" and "actress" could easily serve as either agent or patient. Thus, longer reading times for the ORC-Animate condition compared to the ORC-Inanimate condition that emerge after readers have fixated the verbs most likely capture differences in difficulty associated with memory retrieval, which leads to more rereading of the sentence in the ORC-Animate condition than the ORC-Inanimate condition.

\section{Method}

Participants-Thirty-six students at the University of North Carolina at Chapel Hill participated in this experiment in exchange for course credit. They were all native English speakers and had normal or corrected-to-normal vision.

Materials-Each participant was presented with 36 experimental sentences and 64 filler sentences. The experimental sentences (see 4) were partly adapted from previous work (Gennari \& MacDonald, 2008; Traxler et al., 2005), but new sentences were also created. The two ORC conditions ( $4 \mathrm{~b}$ and $4 \mathrm{c}$ ) were identical to one another except for the head noun. Animate and inanimate head nouns did not differ in length or log frequency, $t \mathrm{~s}<1$ (SUBTLEXus database, Brysbaert \& New, 2009). The embedded noun was always animate. The SRC condition was created by reversing the position of the embedded NP and 
embedded verb in the ORC-Animate condition (see Appendix A for the full set of experimental stimuli).

The experimental sentences were counterbalanced across three lists so that each participant saw only one version of each item and so that each participant saw the same number of sentences from each of the three conditions. A true/false comprehension question followed every sentence. For the experimental sentences, two-thirds of the questions asked about the action being described in the $\mathrm{RC}$, whereas the other third asked about the action being described in the main clause (King \& Just, 1991). For half of the questions the correct answer was true and for the other half it was false.

Procedure-Participants' eye movements were recorded with an EyeLink 1000 system (SR Research) at a sampling rate of $1000 \mathrm{~Hz}$, which was calibrated at the beginning of each session. A chinrest was used to minimize head movement. Participants were instructed to read at a natural pace. At the start of each trial, a fixation point was presented near the left edge of the monitor, marking the location where the first word of the sentence would appear. When the participant's gaze was steady on this point, the experimenter initiated presentation of the sentence. After reading the sentence, the participant pressed a button, which caused the sentence to disappear and a true-false comprehension question to appear in its place. Participants pressed one button to answer "true," and another button to answer "false." After the participant answered the comprehension question, the fixation point for the next trial appeared.

Participants were first presented with four of the filler sentences. After this warm-up block, the remaining 96 sentences were presented in a different random order for each participant. The experimenter monitored gaze location throughout the experimental session and recalibrated the tracker as necessary.

Analysis-Analysis of the eye-tracking data focused on three standard measures (see Clifton, Staub, \& Rayner, 2007, for a discussion). First-pass reading time is the sum of all initial fixations on a region given the eyes have not yet gone beyond the region; it begins when the region is first fixated and ends when gaze is directed away from the region, either to the left or the right. First-pass reading time for a single word is referred to as gaze duration. We therefore use the term first-pass reading time to describe early processing effects on a multiword region and the term gaze duration to describe early processing effects on a single word or a single word and its preceding determiner. Regression-path duration (also called go-past time) includes all fixation durations from the first fixation in a region until gaze is directed away from the region to the right. Thus, regression-path duration includes time spent rereading earlier parts of the sentence before the reader is ready to proceed with the rest of the sentence. Total time is the sum of all fixation durations on a word or region.

Differences in the processing of ORCs versus SRCs were assessed by analyzing reading times for two regions of interest: the $\mathrm{RC}$ and the matrix verb. The $\mathrm{RC}$ was analyzed as a single region to control for the different word orders of ORCs and SRCs. This region consisted of the three words between the complementizer and the matrix verb. Differences 
in the processing of ORC-Animate and ORC-Inanimate sentences were further assessed by analyzing reading times separately for NP2 and the embedded verb, which consist of the same words in the two conditions.

An automatic procedure in the EyeLink software combined fixations that were shorter than $80 \mathrm{~ms}$ and within one character of another fixation into one fixation. Additional fixations shorter than $80 \mathrm{~ms}$ and longer than 1,000 ms were removed. In addition, maximum cutoff values for the three reading-time measures were set at 3,000 ms.

\section{Results}

Comprehension-question accuracy-Mean comprehension-question accuracies for each condition were as follows: SRC (85\%), ORC-Animate (80\%), ORC-Inanimate (89\%). A one-way repeated-measures ANOVA showed that accuracy differed by condition, $F_{1}(2$, $70)=5.31, M S E=139, p<.01 ; F_{2}(2,70)=5.90, M S E=125, p<.01$. Follow-up comparisons showed that performance was significantly worse on questions following ORCAnimates compared to questions following ORC-Inanimates, $F_{1}(1,35)=7.83, M S E=187$, $p<.01 ; F_{2}(1,35)=10.51, M S E=140, p<.01$. In addition, performance was marginally worse on questions following ORC-Animates than questions following $\operatorname{SRCs}, F_{1}(1,35)=$ $3.17, M S E=147, p<.09 ; F_{2}(1,35)=3.21, M S E=145, p<.09$, and performance was marginally worse on questions following SRCs than questions following ORC-Inanimates, $F_{1}(1,35)=3.39, M S E=82, p<.08 ; F_{2}(1,35)=3.09, M S E=90, p<.09$.

RC region-Mean reading times for the RC region and matrix verb are presented in Table 1. Analysis of first-pass reading time on the $\mathrm{RC}$ region revealed no significant differences among the three conditions. In contrast, there were significant differences in regression-path duration, $F_{1}(2,70)=17.00, M S E=15,546, p<.001 ; F_{2}(2,70)=12.45, M S E=20,607, p<$. 001 , and total time, $F_{1}(2,70)=18.06, M S E=25,914, p<.001 ; F_{2}(2,70)=6.37, M S E=$ $63,019, p<.005$. Follow-up comparisons showed a robust ORC-SRC processing difference, with longer reading times for ORC-Animates compared to SRCs on regression-path duration, $F_{1}(1,35)=32.08, M S E=16,448, p<.001 ; F_{2}(1,35)=23.72, M S E=21,610, p<$. 001 , and total time, $F_{1}(1,35)=28.14, M S E=20,069, p<.001 ; F_{2}(1,35)=13.48, M S E=$ $42,004, p<.005$. Similarly, ORC-Inanimates were more difficult than SRCs in regressionpath duration, $F_{1}(1,35)=9.12, M S E=12,264, p<.01 ; F_{2}(1,35)=7.23, M S E=15,799, p$ $<.02$, but not in total time. Finally, ORC-Animates were more difficult than ORCInanimates in both regression-path duration, $F_{1}(1,35)=8.57, M S E=17,925, p<.01 ; F_{2}(1$, $35)=5.85, M S E=24,413, p<.05$, and total time, $F_{1}(1,35)=23.47, M S E=34,785, p<$. $001 ; F_{2}(1,35)=8.84, M S E=72,033, p<.01$. The locus of this animacy difference is examined in greater detail below.

Matrix verb-Analysis of gaze duration on the matrix verb revealed no significant differences among the three conditions. In contrast, there were significant differences in regression-path duration (though only in the subject analysis), $F_{1}(2,70)=3.30, M S E=$ $13,923, p>.05 ; F_{2}(2,70)=1.59, M S E=20,863, p>.10$, and total time, $F_{1}(2,70)=3.22$, $M S E=17,862, p<.05 ; F_{2}(2,70)=4.59, M S E=13,736, p<.02$. Follow-up comparisons revealed longer reading times for ORC-Animates compared to SRCs in regression-path 
duration (marginal in the item analysis), $F_{1}(1,35)=5.33, M S E=16,694, p<.05 ; F_{2}(1,35)$ $=3.56, M S E=18,250, p<.07$. In addition, SRCs were more difficult than ORC-Inanimates in total time, $F_{1}(1,35)=6.47, M S E=17,147, p<.02 ; F_{2}(1,35)=6.72, M S E=18,006, p<$. 02 . No other pairwise comparisons were significant.

Regions within the ORCs-The differences obtained between the ORC-Animate and ORC-Inanimate conditions at the RC region were examined further by comparing these two conditions at both NP2 and the embedded verb (note that these words are identical for these two conditions). Mean reading times for these two regions are presented in Table 2. There were no significant differences in gaze duration at either NP2 or the embedded verb. In contrast, there were significantly longer reading times on NP2 for ORC-Animates compared to ORC-Inanimates in measures of both regression-path duration, $F_{1}(1,35)=6.93, M S E=$ $8,973, p<.02 ; F_{2}(1,35)=4.32, M S E=13,311, p<.05$, and total time, $F_{1}(1,35)=10.79$, $M S E=25,711, p<.005 ; F_{2}(1,35)=8.34, M S E=29,775, p<.01$. Analysis of regressionpath duration at the embedded verb revealed no significant differences; however, analysis of total time at this region revealed longer times for the ORC-Animate condition compared to the ORC-Inanimate condition (marginal in the item analysis), $F_{1}(1,35)=5.66, M S E=$ $12,783, p<.05 ; F_{2}(1,35)=3.39, M S E=19,423, p<.08$.

\section{Discussion}

The results of Experiment 1 showed that ORCs were more difficult to process than SRCs, as indicated by worse performance on comprehension questions, longer regression-path durations and total times at the RC region, and longer regression-path durations at the matrix verb. This pattern replicates previous work that has examined ORC-SRC differences using eye-tracking methodology (e.g., Gordon et al., 2006; Johnson et al., 2011; Lowder \& Gordon, 2012; Traxler et al., 2002, 2005). In addition, these results are consistent with previous claims that ORCs are easier to process when NP1 is inanimate and NP2 is animate (Gennari \& MacDonald, 2008; Traxler et al., 2002, 2005). Previous work has compared these structures to ORCs with the reverse animacy configuration (i.e., animate NP1, inanimate NP2) and with different embedded verbs. Because the current experiment manipulated only NP1 while holding NP2 and the embedded verb constant, its findings establish the role of NP1 animacy more conclusively than previous experiments that varied the animacy of NP1 and NP2 together and which used different embedded verbs across conditions. The results showed that the ORC-Animate condition was more difficult than the ORC-Inanimate condition as early as regression-path duration on NP2 (i.e., before any verbs had been encountered). This pattern in the eye-tracking data is consistent with the self-paced reading results of Gennari and MacDonald, who also found an animacy effect on NP2. Gennari and MacDonald argued that this effect stems from differences in readers' expectations regarding how a sentence with an animate NP1 versus an inanimate NP1 is most likely to unfold.

In addition to the early effect of animacy at NP2, differences between the ORC-Animate and ORC-Inanimate conditions were also observed in comprehension-question accuracies and in total time at NP2 and the embedded verb. In contrast to the expectation-based explanation for the early animacy effect, these differences most likely reflect differences in the 
reversibility of NP-verb pairings between the ORC-Animate and ORC-Inanimate conditions. Whereas the inclusion of one animate and one inanimate NP in the ORC-Inanimate condition can facilitate readers' assignment of thematic roles, the inclusion of two animate NPs in the ORC-Animate condition requires readers to focus more closely on the syntactic structure of the sentence in order to understand who did what to whom. This difference explains why participants spent more time rereading NP2 and the embedded verb in the ORC-Animate compared to the ORC-Inanimate condition and why comprehension was worse.

Differences in reversibility also explain why comprehension-question accuracy was lower for SRCs than ORC-Inanimates and why total time on the matrix verb was longer for SRCs than for ORC-Inanimates. Even though the syntactic structure of the SRCs was simpler than that of the ORC-Inanimate condition, the inclusion of two animate NPs in the SRC condition made the relationships between NPs and verbs more easily confusable than in the ORCInanimate condition.

\section{Experiment 2}

Experiment 1 produced results that are consistent with Gennari and MacDonald's (2008) finding that the animacy of NP1 can have an early effect on ORC processing. Gennari and MacDonald argue that their pattern of results can be explained in terms of semantic indeterminacy, where readers use the animacy of NP1 to quickly generate expectations about how the sentence is most likely to unfold, and processing difficulty thus reflects violations of those expectations. In the current experiment, we assess whether the influence of NP1 animacy on ORC processing depends further on differences in the degree of semantic relatedness between NP1 and NP2. This research question was driven in part by the observation that some of Gennari and MacDonald's critical NPs shared a tight semantic relationship in the sense that the referents of the two NPs were likely to participate in the same event (e.g., The movie that the director...; The trial that the lawyer...), whereas others seemed to have been paired in an arbitrary manner (e.g., The accident that the musician...; The meal that the minister...). In this experiment, we tested ORC sentences like those in (5), where the only word that differed across conditions was the head noun. Whereas the head nouns in (5a) and (5b) share a close semantic relationship with NP2, the head nouns in (5c) and (5d) were chosen arbitrarily such that the referents of the two NPs were unlikely to participate in the same event. In addition, the head noun could be animate $(5 \mathrm{a} \& 5 \mathrm{c})$ or inanimate $(5 \mathrm{~b} \& 5 \mathrm{~d})$.

(5a) The mayor that the senator criticized received more publicity than anyone expected. (Animate-Related)

(5b) The bills that the senator criticized received more publicity than anyone expected. (Inanimate-Related)

(5c) The waitress that the senator criticized received more publicity than anyone expected. (Animate-Arbitrary)

(5d) The recipe that the senator criticized received more publicity than anyone expected. (Inanimate-Arbitrary) 
We assume that during ORC processing readers attempt to establish a meaningful relation between NP1 and NP2 as soon as they can. The comparisons outlined in (5) illustrate that readers have multiple sources of semantic information available to them during processing. In the Related condition, a tight semantic relationship exists between NP1 and NP2, and we predicted that readers would use this relationship to establish a meaningful association between the two referents before encountering any verbs. In contrast, there is no preexisting semantic link between NP1 and NP2 in the Arbitrary condition. When readers can no longer use semantic relatedness to associate the two NPs, we predicted that they would rely on the animacy of the NPs to begin establishing how the two NPs might relate to one another.

Thus, if early processing in the Related condition is driven more by the preexisting semantic link between NP1 and NP2 than animacy information, then the early effect of NP1 animacy (i.e., regression-path duration at NP2) should be smaller in the Related condition than in the Arbitrary condition.

\section{Method}

Participants-Forty-four students at the University of North Carolina at Chapel Hill participated in this experiment in exchange for course credit. They were all native English speakers and had normal or corrected-to-normal vision. None had participated in Experiment 1.

Materials, Procedure, and Analysis-Each participant was presented with 36 experimental sentences and 88 filler sentences. The experimental sentences (see 5) were all ORCs that were adapted from the materials used in Experiment 1. The words across all four conditions were identical except for the head noun. Across conditions, head nouns did not differ in $\log$ frequency, $F(3,140)<1, p>.48$ (SUBTLEXus database, Brysbaert \& New, 2009 ), or length $F(3,140)=1.15, p>.33$. As in Experiment 1, the embedded noun was always animate. Closeness of the semantic relationship between N1 and N2 was assessed using Latent Semantic Analysis (LSA; Landauer \& Dumais, 1997), which derives semantic similarity from patterns of word co-occurrence across a large sample of text. The mean LSA scores between $\mathrm{N} 1$ and $\mathrm{N} 2$ in the Related condition (.38) were significantly higher than the mean LSA scores between N1 and N2 in the Arbitrary condition $(.05), F(1,142)=149, p<$. 001. See Appendix B for the full set of experimental stimuli.

The experimental sentences were counterbalanced across four lists so that each participant saw only one version of each item and so that each participant saw the same number of sentences from each of the four conditions. All other aspects of the procedure were identical to the procedure described in Experiment 1. As in Experiment 1, analysis of eye-tracking data in Experiment 2 focused on gaze duration, regression-path duration, and total time. Finally, the same data-exclusion criteria described in Experiment 1 were also employed here.

\section{Results}

Comprehension-question accuracy-Mean comprehension-question accuracies for each condition were as follows: Animate-Related (83\%), Inanimate-Related (89\%), Animate-Arbitrary (82\%), Inanimate-Arbitrary (90\%). There was a significant main effect 
of animacy, such that performance was worse on questions following ORCs with animate heads compared to questions following ORCs with inanimate heads, $F_{1}(1,43)=11.71, M S E$ $=195, p<.005 ; F_{2}(1,35)=7.73, M S E=241, p<.01$. Neither the main effect of semantic relatedness nor the interaction between animacy and relatedness were significant, $F \mathrm{~s}<1, p \mathrm{~s}$ $>.64$.

NP2-Reading times are presented in Table 3. Analysis of gaze duration at NP2 revealed no significant main effects or interactions. In contrast, analysis of regression-path duration revealed a significant main effect of animacy (marginal in the item analysis), such that there were longer reading times for the Animate condition compared to the Inanimate condition, $F_{1}(1,43)=4.18, M S E=10,124, p<.05 ; F_{2}(1,35)=3.45, M S E=11,833, p<.08$. A similar pattern also emerged in analysis of total time, $F_{1}(1,43)=9.47, M S E=22,595, p<.005$; $F_{2}(1,35)=6.10, M S E=29,192, p<.02$. In addition, there were significant main effects of relatedness for both regression-path duration, $F_{1}(1,43)=5.00, M S E=12,240, p<.05 ; F_{2}(1$, $35)=4.22, M S E=13,853, p<.05$, and total time, $F_{1}(1,43)=6.71, M S E=24,660, p<.02$; $F_{2}(1,35)=8.33, M S E=17,262, p<.01$, with longer reading times in the Arbitrary condition compared to the Related condition.

Crucially, there was a significant animacy-by-relatedness interaction in analysis of regression-path duration, $F_{1}(1,43)=6.00, M S E=16,271, p<.02 ; F_{2}(1,35)=5.08, M S E=$ $13,406, p<.05$. Planned contrasts showed that the Arbitrary-Animate condition was more difficult than the Arbitrary-Inanimate condition, $t_{1}(43)=3.37, p<.005 ; t_{2}(35)=2.64, p<$. 02 , whereas there was no difference between the Related-Animate and Related-Inanimate conditions, $t s<1$. In addition, the Arbitrary-Animate condition was more difficult than the Related-Animate condition, $t_{1}(43)=3.61, p<.005 ; t_{2}(35)=3.41, p<.005$, whereas there was no difference between the Arbitrary-Inanimate and Related-Inanimate conditions, $t \mathrm{~s}<1$.

Embedded verb-Main effects of animacy emerged in both gaze duration (marginal in the item analysis), $F_{1}(1,43)=4.19, M S E=3,215, p<.05 ; F_{2}(1,35)=3.32, M S E=2,487, p$ $<.08$, and in total time (significant only in the subject analysis), $F_{1}(1,43)=6.65, M S E=$ $9,872, p<0.2 ; F_{2}(1,35)=2.71, M S E=22,533, p>.10$. Whereas reading times were longer for the Inanimate condition compared to the Animate condition in gaze duration, the opposite pattern emerged in total time.

Main effects of relatedness at the embedded verb emerged in all three reading-time measures, with longer times in the Arbitrary condition than the Related condition. These effects were significant in the subject analysis for gaze duration (marginal in the item analysis $), F_{1}(1,43)=6.40, M S E=2,458, p<.02 ; F_{2}(1,35)=3.55, M S E=3,773, p<.07$, and total time, $F_{1}(1,43)=4.49, M S E=11,321, p<.05 ; F_{2}(1,35)=2.83, M S E=14,741, p$ $>.10$, but were fully significant in regression-path duration, $F_{1}(1,43)=12.50, M S E=7,106$, $p<.005 ; F_{2}(1,35)=5.64, M S E=10,941, p<.05$. The animacy-by-relatedness interaction was not significant in any measure.

Matrix verb-Analysis of regression-path duration revealed a significant main effect of animacy at the matrix verb, such that times were longer in the Animate condition than the Inanimate condition, $F_{1}(1,43)=13.66, M S E=19,112, p<.005 ; F_{2}(1,35)=10.05, M S E=$ 
$21,147, p<.005$. A similar pattern emerged in analysis of total time (significant only in the subject analysis), $F_{1}(1,43)=4.15, M S E=9,446, p<.05 ; F_{2}(1,35)=2.49, M S E=15,752, p$ $>$.10. There were no other significant main effects or interactions.

\section{Discussion}

The results of Experiment 2 showed that ORCs with animate compared to inanimate heads elicited early processing difficulty only when there was no straightforward semantic relationship between the critical NPs. In contrast, when a meaningful relationship existed between NP1 and NP2, no animacy differences were observed until readers had begun processing the verbs of the sentence. As in Experiment 1, these later animacy differences likely reflect the differences in reversibility between the Animate and Inanimate conditions; whereas the thematic roles of NP1 and NP2 in the Animate condition were always reversible, this was usually not the case in the Inanimate condition. In addition to these animacy effects, main effects of relatedness also emerged (i.e., total time at NP2, as well as gaze duration, regression-path duration, and total time at the embedded verb). These patterns reflect readers' overall greater ease of processing ORCs when the critical NPs are entities that are typically associated with one another compared to when the NPs are paired arbitrarily.

Early difficulty with ORC processing seems to arise from at least two different sources. As readers begin processing the first two NPs of an ORC, they attempt to relate them to one another even before any verbs have been encountered. If these two NPs are semantically related to one another (e.g., The mayor that the senator...; The bills that the senator...), readers will proceed to the verbs of the sentence without experiencing any early difficulty at NP2. In contrast, if there is no obvious semantic connection between the two NPs (e.g., The waitress that the senator...; The recipe that the senator...), readers may then rely on the animacy of NP1 to establish an initial meaningful relation between the two NPs. This strategy leads to easier processing when NP1 is inanimate than when it is animate, as readers can more easily understand that the head NP is the object of the RC when it is inanimate than when it is animate. In contrast, later difficulty with ORC processing likely stems from memory-retrieval processes related to the reversibility of NP1 and NP2. When both of the critical NPs are animate, readers experience difficulty remembering which NPs should receive which thematic roles and are more likely to reread earlier parts of the sentence compared to when thematic roles can be assigned on the basis of animacy differences.

\section{General Discussion}

The two experiments reported in this paper demonstrate that the ease of understanding ORCs is influenced by both the animacy of NP1 and the degree of semantic relatedness between NP1 and NP2. Experiment 1 showed that ORCs are more difficult to process when NP1 is animate than when it is inanimate, even when all other words in the sentence are held constant across conditions. This effect of animacy emerged relatively early in processing, before any verbs had been fixated. Experiment 2 replicated the early effect of animacy that was observed in Experiment 1, but only when there was no straightforward semantic link between NP1 and NP2. In contrast, when NP1 and NP2 were semantically related, the early 
effect of NP1 animacy disappeared. Later effects of NP1 animacy emerged in both experiments.

Previous studies that have investigated the effects of NP animacy on RC processing (Gennari \& MacDonald, 2008, 2009; Mak et al., 2002, 2006; Traxler et al., 2002, 2005) have found that ORCs are more difficult when NP1 is animate and NP2 is inanimate compared to the reverse animacy configuration. As described above, these experiments have typically manipulated the animacy of NP1 and NP2 simultaneously, which leads to difficulty in identifying the true source of the reported effects. In Lowder and Gordon (2012), we manipulated the animacy of NP2 while holding the rest of the sentence constant. ORCs with an inanimate compared to an animate NP2 were more difficult to process, but we demonstrated that this effect stemmed from local difficulty associated with integrating an inanimate NP with a verb (e.g., article accused) rather than global difficulty associated with the complex syntax of an ORC. In the current study, we manipulated the animacy of NP1 while holding the rest of the sentence constant. ORCs with an animate compared to an inanimate NP1 were more difficult to process at NP2. Although this pattern is consistent with previous findings using self-paced reading (Gennari \& MacDonald, 2008), the explanation for this early effect is less clear. Gennari and MacDonald propose that difficulty associated with processing ORCs can be explained largely as a function of violation of readers' expectations. According to this account, an animate NP1 followed immediately by an animate NP2 is less expected than an inanimate NP1 followed by an animate NP2, which explains the reading-time differences at NP2. Although the current study cannot rule out an expectation-based explanation of this phenomenon, another possibility is that inflated reading times at NP2 reflect processes that operate under a memory-based framework of RC processing (e.g., Gordon et al., 2001, 2002, 2004, 2006; Lewis \& Vasishth, 2005; Lewis et al., 2006). Accounts of this sort conceptualize ORC difficulty as stemming from processes associated with memory encoding, storage, and retrieval. Thus, the early NP2 effects observed in the current study could reflect an encoding-based strategy in which readers anticipate that they will experience more difficulty remembering two animate NPs than one inanimate and one animate NP, and so they adjust their encoding times accordingly (see also Gordon \& Lowder, 2012; Johnson et al., 2011). Importantly, these two explanations do not necessarily provide mutually exclusive accounts of early animacy effects in RC processing; in principle, both could explain some aspects of the observed difficulty. Further, it is possible that the accounts may differ with respect to how well they explain animacy-by-RCtype interactions obtained in different languages, such as Dutch (Mak et al., 2002, 2006), Korean (Kwon, Lee, Gordon, Kluender, \& Polinsky, 2010; Lee, Lee, \& Gordon, 2007), and English (see Gordon \& Lowder, 2012; Lee, Lee, Gordon, \& Hendrick, 2010).

Importantly, Experiment 2 showed that the early animacy effect at NP2 disappeared completely when NP1 and NP2 were semantically related. This pattern suggests that previous demonstrations of an early animacy effect (Experiment 1; Gennari \& MacDonald, 2008) may have been driven by a subset of experimental materials in which NP1 and NP2 were paired arbitrarily. We propose that as readers begin processing an ORC, they attempt to establish meaningful relations between NP1 and NP2 before encountering the verbs of the sentence. When NP1 and NP2 share a close semantic link, readers can use this information 
to form an initial representation of these two referents participating in the same event, regardless of whether the NPs are both animate (e.g., The mayor that the senator...) or the first is inanimate (e.g., The bills that the senator...). Readers then easily proceed to the verbs of the sentence to understand more specifically how the two referents relate to one another in the event. In contrast, when there is no straightforward semantic link between NP1 and NP2, readers can make use of information about the animacy of the two NPs to help form an understanding of how these two referents may be interacting in an event. When NP1 is inanimate and NP2 is animate (e.g., The recipe that the senator...), readers can easily understand that the inanimate NP1 is the object of the action being described in the RC, and so they proceed to the verbs of the sentence. However, when there is no semantic link between the two NPs and they do not differ in animacy (e.g., The waitress that the senator...), then readers have difficulty establishing an initial meaningful relation between them, and so slowdown begins at NP2.

Both experiments produced evidence of animacy effects in later reading-time measures and in comprehension-question accuracies. In contrast to the early effects, these later effects likely reflect differences in ease of memory retrieval. When NP1 was inanimate and NP2 was animate, the actions described in the sentence were rarely semantically reversible (e.g., The movie that the actress hated...), and so readers could rely on their knowledge of the world to assign thematic roles appropriately. In contrast, when both NPs were animate, the actions described in the sentence were always semantically reversible (e.g., The director that the actress hated...), and so readers could not rely on world knowledge but had to attend to the syntactic structure of the sentence in order to assign thematic roles appropriately. In cases where readers did not carefully encode the order of the two NPs, they may have experienced difficulty when the NPs later had to be retrieved from memory and integrated with the verbs of the sentence. Thus, participants were more likely to go back and reread the sentence when both NPs were animate, so that they knew which NP was the agent and which was the patient.

\section{Conclusion}

Processing of complex syntactic structures is influenced by a wide variety of lexical, semantic, and pragmatic factors. The experiments reported here examined how two semantic factors-animacy and NP relatedness-influence both early and later stages of complexsentence processing. The results demonstrate that object-relative clauses with an inanimate compared to an animate NP1 can facilitate early processing, but only when there is no straightforward semantic relationship between NP1 and NP2. When the two critical NPs do share a strong semantic link, readers will use this information rather than animacy information to form an initial representation of the two referents participating in the same event. In addition, differences in NP animacy influence later stages of complex-sentence processing, regardless of the relationship between NP1 and NP2. We believe that these later effects emerge as a result of memory-retrieval processes that operate during the assignment of thematic roles. 


\section{Acknowledgments}

This research was supported by R01 HD060440-06A2 from NICHD. We thank Laura deSouza and Rachael Jones for assistance in conducting the experiments and Giulia Pancani for helpful comments on a draft of this article.

\section{Appendix A}

The stimuli from Experiment 1 are shown below in their object-extracted forms with both animate and inanimate head NPs. Each item was also presented in its subject-extracted form, as described in the text.

1. The $\{$ hikers/avalanche $\}$ that the ranger followed buried the climbers after they fell from the top of the mountain.

2. The \{farmer/tractor $\}$ that the peasant detested ruined the crops before we even had a chance to harvest anything.

3. The $\{$ cowboy/pistol $\}$ that the sheriff feared injured a man in the bar fight last night.

4. The $\{$ driver/accident $\}$ that the bicyclist avoided crippled a skateboarder on that tragic day last June.

5. The \{plumber/wrench $\}$ that the intruder spotted bruised the handyman yesterday afternoon.

6. The $\{$ burglar/revolver $\}$ that the policeman found shot the deputy in the abandoned warehouse.

7. The $\{$ reporter/sword $\}$ that the historian photographed wounded the president in a surprise attack.

8. The $\{$ killer/weapon $\}$ that the detective located slaughtered innocent victims over the last ten years.

9. The $\{$ landscaper/wagon $\}$ that the boy saw dragged the statue from one end of the yard to the other.

10. The $\{$ boys/church $\}$ that the hobo visited sheltered many people last winter.

11. The $\{$ athlete/sponge $\}$ that the cheerleader liked washed the truck the day after we drove through that big mud puddle.

12. The $\{$ author/book $\}$ that the editor praised dominated the competition at the annual literary awards ceremony.

13. The $\{$ kids/pizza $\}$ that the neighbors loved fed the guests at the Christmas party.

14. The $\{$ farmer/crops $\}$ that the maiden nurtured sustained the town after the successful harvest last fall.

15. The \{girls/feathers $\}$ that the toddlers adored tickled the boys in the South African village.

16. The $\{$ painter/plants $\}$ that the gardener opposed improved the appearance of the house after the work was completed. 
17. The \{senator/article $\}$ that the journalist criticized accused the governor of embezzling millions of dollars.

18. The $\{$ student/school $\}$ that the teacher observed taught many immigrants who were trying to learn English.

19. The \{diplomat/painting $\}$ that the queen despised entered the gallery just before the auction was scheduled to begin.

20. The \{groupies/trailers $\}$ that the musicians wanted carried the equipment to the next performance.

21. The $\{$ pilot/helicopter $\}$ that the captain directed transferred the soldiers to the nearest hospital.

22. The $\{$ engineer/rocket $\}$ that the commander supervised lifted the supplies into the air.

23. The $\{$ warrior/spear $\}$ that the gladiator threw impaled many opponents in the Coliseum.

24. The $\{$ clerk/machine $\}$ that the manager hated injured some employees in the accident.

25. The $\{$ child/puddle $\}$ that the babysitter noticed destroyed the basement within a matter of hours.

26. The $\{$ director/movie $\}$ that the actress loathed defeated the competitors at the film festival.

27. The $\{$ soldiers/camp $\}$ that the rebels attacked housed the fugitives somewhere in the middle of the forest.

28. The $\{$ punk/knife $\}$ that the officer grabbed wounded a woman during the struggle.

29. The $\{\mathrm{maid} / \mathrm{broom}\}$ that the guest ignored cleared the dirt off the sidewalk yesterday morning.

30. The $\{$ expert/device $\}$ that the architect trusted assisted the carpenter as he built the new house.

31. The \{guards/rifles $\}$ that the activists condemned killed many prisoners over the past five years.

32. The $\{$ novice/hook $\}$ that the expert watched pulled the fish closer to the pier where everyone was standing.

33. The $\{$ worker/metal $\}$ that the supervisor encountered poisoned several men who were working in the mine.

34. The $\{$ technician/mineral $\}$ that the scientist assessed broke the test tubes in the laboratory.

35. The $\{$ cadets/fort $\}$ that the spies defeated protected the city from enemies for many more years. 
36. The \{executive/airplane $\}$ that the employee chose transported the documents to New York in time for the meeting.

\section{Appendix B}

The stimuli from Experiment 2 are shown below with all four types of head NPs. Within a set of brackets, the nouns correspond to the Animate-Related, Inanimate-Related, AnimateArbitrary, and Inanimate-Arbitrary conditions, respectively.

1. The $\{$ ranger/avalanche/secretary/tsunami $\}$ that the hikers followed moved quickly down the side of the mountain.

2. The $\{$ worker/tractor/banker/convertible $\}$ that the farmer detested stood next to the barn.

3. The $\{$ cowboy/pistol/butcher/cleaver $\}$ that the sheriff feared injured a man in the bar fight last night.

4. The $\{$ driver/accident/terrorist/eruption $\}$ that the bicyclist avoided caused a number of serious injuries.

5. The $\{$ handyman/wrench/jeweler/necklace $\}$ that the plumber spotted stayed in the back room.

6. The $\{$ burglar/revolver/king/crown $\}$ that the policeman found remained in the cottage.

7. The $\{$ celebrity/event/knight/sword $\}$ that the reporter photographed attracted a great deal of attention.

8. The $\{$ killer/weapon/baker/bread $\}$ that the detective located appeared on the television program.

9. The $\{$ landscaper/clippers/librarian/bookcase $\}$ that the gardener saw rested against the side of the house.

10. The $\{$ girls/games/chief/floor $\}$ that the boys disliked became more appealing with each passing year.

11. The $\{$ athlete/skirt/judge/verdict $\}$ that the cheerleader liked seemed very reasonable to all of us.

12. The $\{$ author/book/chef/cake $\}$ that the editor praised dominated the competition at the festival.

13. The $\{$ friends/toys/expert/utensils $\}$ that the kids loved worried all of the adults who were in the room.

14. The $\{$ patient/wound/lawyer/table $\}$ that the nurse cleaned required a lot of extra attention.

15. The $\{$ babysitter/cartoons/colonel/magazine $\}$ that the toddlers adored entertained them for hours on end. 
16. The $\{$ sculptor/portrait/janitor/furniture $\}$ that the painter opposed improved the appearance of the gallery.

17. The $\{$ mayor/bills/waitress/recipe $\}$ that the senator criticized received more publicity than anyone expected.

18. The $\{$ student/school/victim/hospital $\}$ that the teacher observed developed many serious problems that needed to be addressed.

19. The $\{$ princess/castle/comedian/comedy $\}$ that the queen despised charmed all of the other dinner guests.

20. The $\{$ conductor/instruments/caterer/snacks $\}$ that the musicians preferred arrived right before the concert began.

21. The $\{$ copilot/helicopter/minister/tank $\}$ that the pilot directed transferred the soldiers to the nearest hospital.

22. The $\{$ builder/rocket/rancher/orchard $\}$ that the engineer supervised impressed everyone last week.

23. The $\{$ damsel/kingdom/neighbor/embassy $\}$ that the hero protected triggered a conflict that wasn't resolved for years.

24. The $\{$ clerk/store/priest/church $\}$ that the manager hated offended many citizens of the town.

25. The $\{$ swimmer/waves/fugitive/rifle $\}$ that the lifeguard noticed disappeared into the vast ocean.

26. The $\{$ director/movie/dentist/cavity $\}$ that the actress loathed cost more money than we had anticipated.

27. The $\{$ enemy/fort/waiter/restaurant $\}$ that the soldiers attacked held a great deal of important information.

28. The $\{$ spy/gun/singer/broom $\}$ that the officer grabbed wounded a woman during the struggle.

29. The $\{$ employee/report/pianist/piano $\}$ that the executive ignored caught the attention of everyone else at the company.

30. The $\{$ designer/design/fisherman/cuisine $\}$ that the architect trusted looked very appealing to the new client.

31. The $\{$ doctor/operation/writer/novel $\}$ that the surgeon remembered taught us several valuable lessons last night.

32. The $\{$ skipper/ship/cashier/ball $\}$ that the captain watched turned unexpectedly toward the rocks.

33. The $\{$ biologist/plants/artist/article $\}$ that the botanist encountered influenced the scientific community profoundly. 
34. The $\{$ technician/mineral/juggler/mallets $\}$ that the scientist assessed broke the test tubes in the laboratory.

35. The $\{$ guitarist/cymbals/foreigner/phone $\}$ that the drummer enjoyed produced the clearest sound we had ever heard.

36. The $\{$ leader/leadership/photographer/photographs $\}$ that the president retained fascinated the media for several weeks.

\section{References}

Brysbaert M, New B. Moving beyond Kucera and Francis: A critical evaluation of current word frequency norms and the introduction of a new and improved word frequency measure for American English. Behavior Research Methods. 2009; 41:977-990. [PubMed: 19897807]

Caplan D, Alpert N, Waters G. Effects of syntactic structure and propositional number on patterns of regional cerebral blood flow. Journal of Cognitive Neuroscience. 1998; 10:541-552. [PubMed: 9712683]

Caramazza A, Zurif E. Dissociation of algorithmic and heuristic processes in sentence comprehension: Evidence from aphasia. Brain and Language. 1976; 3:572-582. [PubMed: 974731]

Clifton, CE., Jr.; Frazier, L. Comprehending sentences with long-distance dependencies. In: Carlson, GH.; Tanenhaus, MK., editors. Linguistic structure in language processing. Kluwer; Dordrecht: 1989. p. 273-317.

Clifton, C., Jr.; Staub, A.; Rayner, K. Eye movements in reading words and sentences. In: van Gompel, RPG.; Fischer, MH.; Murray, WS.; Hill, RL., editors. Eye movements: A window on mind and brain. Elsevier; Amsterdam: 2007.

Ford M. A method for obtaining measures of local parsing complexity throughout sentences. Journal of Verbal Learning and Verbal Behavior. 1983; 22:203-218.

Frazier L, Clifrton C Jr. Successive cyclicity in the grammar and the parser. Language and Cognitive Processes. 1989; 4:93-126.

Gennari SP, MacDonald MC. Semantic indeterminacy in object relative clauses. Journal of Memory and Language. 2008; 58:161-187. [PubMed: 19724662]

Gennari S, MacDonald MC. Linking production and comprehension processes: The case of relative clauses. Cognition. 2009; 111:1-23. P. [PubMed: 19215912]

Gordon PC, Hendrick R, Johnson M. Memory interference during language processing. Journal of Experimental Psychology: Learning, Memory, and Cognition. 2001; 27:1411-1423.

Gordon PC, Hendrick R, Johnson M. Effects of noun phrase type on sentence complexity. Journal of Memory and Language. 2004; 51:97-114.

Gordon PC, Hendrick R, Johnson M, Lee Y. Similarity-based interference during language comprehension: Evidence from eye tracking during reading. Journal of Experimental Psychology: Learning, Memory, and Cognition. 2006; 32:1304-1321.

Gordon PC, Hendrick R, Levine WH. Memory-load interference in syntactic processing. Psychological Science. 2002; 13:425-430. [PubMed: 12219808]

Gordon PC, Lowder MW. Complex sentence processing: A review of theoretical perspectives on the comprehension of relative clauses. Language and Linguistics Compass. 2012; 6:403-415.

Hale, J. A probabilistic Earley parser as a psycholinguistic model; Proceedings of NAACL; 2001. p. 159-166.

Holmes VM, O'Regan JK. Eye fixation patterns during the reading of relative-clause sentences. Journal of Verbal Learning and Verbal Behavior. 1981; 20:417-430.

Johnson ML, Lowder MW, Gordon PC. The sentence-composition effect: Processing of complex sentences depends on the configuration of common noun phrases versus unusual noun phrases. Journal of Experimental Psychology: General. 2011; 140:707-724. [PubMed: 21767046]

Just MA, Carpenter PA, Keller TA, Eddy WF, Thulborn KR. Brain activation modulated by sentence comprehension. Science. 1996; 274:114-116. [PubMed: 8810246] 
King J, Just MA. Individual differences in syntactic processing: The role of working memory. Journal of Memory and Language. 1991; 30:580-602.

Kwon N, Lee Y, Gordon PC, Kluender R, Polinsky M. Cognitive and linguistics factors affecting subject/object asymmetry: An eye-tracking study of prenominal relative clauses in Korean. Language. 2010; 86:546-582.

Lee Y, Lee E, Gordon PC, Hendrick R. Commentary on Evans and Levinson, The myth of language universals: Language diversity, cognitive universality. Lingua. 2010; 120:2695-2698.

Lee Y, Lee H, Gordon PC. Linguistic complexity and information structure in Korean: Evidence from eye-tracking during reading. Cognition. 2007; 104:495-534. [PubMed: 16970936]

Levy R. Expectation-based syntactic comprehension. Cognition. 2008; 106:1126-1177. [PubMed: 17662975]

Lewis RL, Vasishth S. An activation-based model of sentence processing as skilled memory retrieval. Cognitive Science. 2005; 29:375-419. [PubMed: 21702779]

Lewis RL, Vasishth S, Van Dyke JA. Computational principles of working memory in sentence comprehension. Trends in Cognitive Sciences. 2006; 10:447-454. [PubMed: 16949330]

Lowder MW, Gordon PC. The pistol that injured the cowboy: Difficulty with inanimate subject-verb integration is reduced by structural separation. Journal of Memory and Language. 2012; 66:819832.

Lowder MW, Gordon PC. It's hard to offend the college: Effects of sentence structure on figurativelanguage processing. Journal of Experimental Psychology: Learning, Memory, \& Cognition. 2013; 39:993-1011.

Lowder MW, Gordon PC. The manuscript that we finished: Structural separation reduces the cost of complement coercion. under review. Manuscript under review.

MacDonald MC, Christiansen MH. Reassessing working memory: Comment on Just and Carpenter (1992) and Waters and Caplan (1996). Psychological Review. 2002; 109:35-54. [PubMed: 11863041]

Mak WM, Vonk W, Schriefers H. The influence of animacy on relative clause processing. Journal of Memory and Language. 2002; 47:50-68.

Mak WM, Vonk W, Schriefers H. Animacy in processing relative clauses: The hikers that rocks crush. Journal of Memory and Language. 2006; 54:466-490.

Staub A. Eye movements and processing difficulty in object relative clauses. Cognition. 2010; 116:7186. [PubMed: 20427040]

Traxler MJ, Morris RK, Seely RE. Processing subject and object relative clauses: Evidence from eye movements. Journal of Memory and Language. 2002; 47:69-90.

Traxler MJ, Williams RS, Blozis SA, Morris RK. Working memory, animacy, and verb class in the processing of relative clauses. Journal of Memory and Language. 2005; 53:204-224.

Wanner, E.; Maratsos, M. An ATN approach to comprehension. In: Halle, M.; Bresnan, J.; Miller, G., editors. Linguistic theory and psychological reality. MIT Press; Cambridge: 1978.

Warren T, Gibson E. The influence of referential processing on sentence complexity. Cognition. 2002; 85:79-112. [PubMed: 12086714] 


\section{Table 1}

Eye-tracking results of relative-clause effects in Experiment 1. Mean reading times are presented with standard errors in parentheses.

\begin{tabular}{lcccc}
\hline Measure (in milliseconds) & & $\underline{\mathbf{R C}}$ & $\underline{\text { Matrix Verb }}$ & \\
SRC & The senator that & criticized the journalist & accused & $\ldots$ \\
ORC-Animate & The senator that & the journalist criticized & accused & $\ldots$ \\
ORC-Inanimate & The article that & the journalist criticized & accused & $\ldots$ \\
\hline First-pass reading time & & & & \\
SRC & $571(28)$ & $347(12)$ & \\
ORC-Animate & $606(27)$ & $335(12)$ & \\
ORC-Inanimate & $604(31)$ & $343(11)$ \\
Regression-path duration & & & \\
SRC & $808(33)$ & $482(25)$ & \\
ORC-Animate & $979(36)$ & $553(26)$ & \\
ORC-Inanimate & $887(33)$ & $529(24)$ & \\
Total time & & $733(48)$ & \\
SRC & $1426(68)$ & $707(36)$ & \\
ORC-Animate & $1603(69)$ & $655(39)$ & \\
ORC-Inanimate & $1390(60)$ &
\end{tabular}

Note. $\mathrm{RC}=$ relative clause; $\mathrm{SRC}=$ subject-extracted relative clause; $\mathrm{ORC}=$ object-extracted relative clause 


\section{Table 2}

Eye-tracking results of animacy effects in Experiment 1. Mean reading times are presented with standard errors in parentheses.

\begin{tabular}{lcccc}
\hline $\begin{array}{c}\text { Measure (in milliseconds) } \\
\text { ORC-Animate }\end{array}$ & $\begin{array}{c}\text { NP2 } \\
\text { The senator that }\end{array}$ & $\begin{array}{c}\text { Embedded Verb } \\
\text { the journalist }\end{array}$ & $\begin{array}{r}\text { criticized } \\
\text { ORC-Inanimate }\end{array}$ & $\ldots$ \\
\hline The article that & the journalist & criticized & $\ldots$ \\
\hline ORC-Animate & & & \\
ORC-Inanimate & $365(17)$ & $336(11)$ & \\
Regression-path duration & $349(17)$ & $331(12)$ \\
ORC-Animate & & \\
ORC-Inanimate & $567(27)$ & $448(21)$ \\
Total time & $509(27)$ & $414(19)$ \\
ORC-Animate & & \\
ORC-Inanimate & $965(57)$ & $767(40)$ \\
\hline
\end{tabular}

Note. $\mathrm{NP}=$ noun phrase $; \mathrm{ORC}=$ object-extracted relative clause 


\section{Table 3}

Eye-tracking results of Experiment 2. Mean reading times are presented with standard errors in parentheses.

\begin{tabular}{|c|c|c|c|c|c|}
\hline Measure (in milliseconds) & & $\underline{\text { NP2 }}$ & Embedded & Matrix & \\
\hline Animate-Related & The mayor that & the senator & criticized & received & $\ldots$ \\
\hline Inanimate-Related & The bills that & the senator & criticized & received & $\ldots$ \\
\hline Animate-Arbitrary & The waitress that & the senator & criticized & received & $\ldots$ \\
\hline Inanimate-Arbitrary & The recipe that & the senator & criticized & received & $\ldots$ \\
\hline \multicolumn{6}{|l|}{ Gaze duration } \\
\hline Animate-Related & & $301(12)$ & $312(11)$ & $328(12)$ & \\
\hline Inanimate-Related & & $313(15)$ & 317 (14) & $317(11)$ & \\
\hline Animate-Arbitrary & & $306(12)$ & $322(10)$ & $330(12)$ & \\
\hline Inanimate-Arbitrary & & $318(13)$ & $352(14)$ & $329(13)$ & \\
\hline \multicolumn{6}{|l|}{ Regression-path duration } \\
\hline Animate-Related & & $458(22)$ & $424(20)$ & $551(34)$ & \\
\hline Inanimate-Related & & $474(27)$ & $397(21)$ & $444(19)$ & \\
\hline Animate-Arbitrary & & $543(27)$ & $460(22)$ & $544(32)$ & \\
\hline Inanimate-Arbitrary & & $465(24)$ & $450(22)$ & $497(32)$ & \\
\hline \multicolumn{6}{|l|}{ Total time } \\
\hline Animate-Related & & $740(42)$ & $649(28)$ & $577(28)$ & \\
\hline Inanimate-Related & & $698(37)$ & $590(29)$ & $534(23)$ & \\
\hline Animate-Arbitrary & & $829(37)$ & $663(32)$ & $593(26)$ & \\
\hline Inanimate-Arbitrary & & $731(36)$ & $645(27)$ & $577(23)$ & \\
\hline
\end{tabular}

Note. $\mathrm{NP}=$ noun phrase. 